\title{
Human Lifespan Approach and High Abilities/Giftedness
}

\author{
Juan José Mouriño Mosquera', Claus Dieter Stobäus' ${ }^{2}$, Soraia Napoleão de Freitas ${ }^{3}$ \\ ${ }^{1}$ Postgraduate Program in Education, Pontifical Chatolic University of Rio Grande do Sul, Porto Alegre, Brazil \\ ${ }^{2}$ Postgraduate Programs in Education and in Biomedical Gerontology, Pontifical Chatolic University of Rio \\ Grande do Sul, Porto Alegre, Brazil \\ ${ }^{3}$ Postgraduate Program in Full Inclusion/Special Education, Federal University of Santa Maria, Santa Maria, \\ Brazil \\ Email: Stobaus@pucrs.br
}

Received 5 February 2015; accepted 30 April 2015; published 5 May 2015

Copyright (C) 2015 by authors and Scientific Research Publishing Inc.

This work is licensed under the Creative Commons Attribution International License (CC BY).

http://creativecommons.org/licenses/by/4.0/

(c) (i) Open Access

\section{Abstract}

The article is based on the studies, discussions and reflections between the authors, about the theme of the High Ability/Giftedness, to enable better understanding of their approach in terms of human development in Childhood, Adolescent and Adulthood, in the so-called lifelong approach/ lifespan approach, because of their transit in the fields of Education, Psychology and Full Inclusion, with some supports of the Neurosciences and newly studies on brain aspects of cognition, intelligence, learning, and cultural influences, in which a subject develops and operates, seeking to explore some aspects of the human development and personality throughout life, relating to social and cultural learning, in the achievement of process of learning, ending with some possibilities on the attendance of those people, connecting with the Health and Positive Psychology.

\section{Keywords}

High Abilities, Giftedness, Adulthood, Lifespan Approach

\section{Introduction}

As we described in another paper (Mosquera, Stobäus, \& Freitas, 2013), our initial concerns to discuss these themes related to the human life development, especially when someone is related to a family or is themselves a High Ability/Gifted-HA/G person, or is a teacher or member of their school or community. To carry out further, in terms of the ideals of these areas, we all must deal with our competences and reflections about: what they really are and how gifted persons live. In our case, we present our study subject as students in order to give an 
overview of how they develop in Childhood, Adolescence and Adulthood, it means, in his/her entire life, considered by us [and many authors as Baltes, Staudinger, \& Lindenberger (1999), Schaie, \& Willis (2003), and also Papalia, Olds, \& Feldman (2010)] as the lifespan approach, by detailing a bit psychological, educational and social processes that are present in these development.

When we speak about their social inclusion, scholar inclusion, familiar inclusion, we are speaking about Full Inclusion, as we pointed (Stobäus \& Mosquera, 2004), and we can say that we now are fully prepared to contemplate all these aspects involved in the attendance of a gifted person.

One of the first authors using the ideas of being better prepared to lead with "different” persons was Vygotsky, who in the 30 and 40 of last century told us about the deficient and the gifted, when he investigated a lot of people in Russia.

In our investigations and when we speak about Full Inclusion, the more that we can do is preparing our society to receive blind, deaf, mentally disabled, wheelchair people/student, and don't forget that there are also gifted persons living in the society. In a recent study we detected more than $7 \%$ of these people in schools, more than the sum of the other aforementioned deficiencies (Stobäus \& Mosquera (2013).

Arroyo, Martorell, \& Tarragó (2006) ask: Who are the gifted? Their responds are those with very high intellectual potential and a high capacity of new and original ideas. In its publications, the authors approach the world of high ability/gifted from the experiences of gifted themselves. Understand giftedness as a complex profile, which is defined around three axes, and not just a single feature to determine HA/G: Intelligence, Personality and Creativity.

As for intelligence, for these authors, intellectual giftedness implies having a great potential in at least one of the areas that make up the human intelligence, accompanied by a high capacity for creative thinking tasks and able to combine these aspects with an innovative and different outcome that distinguishes "high intellectual capacity"; we must distinguish between precocity and intellectual giftedness.

The intellectual precocity is part of the evolutionary phenomenon, a larger initial intellectual development, compared to other people of the same chronological age. People with high ability/gifted (those with HA/G) have a high capacity in relation to one/more aspect(s) of intelligence or even a great skill for a skill, or a specific behavior. People possess exceptional intelligence and this differentiates from what we consider "normal", from their speed in solve problems and "take it ease" when they have to learn/are learning, and how they combine and utilize especially the knowledge/abilities with another information using creativity, and they also processes and applies information rapidly, applicating the results for their peers in school, family and society.

With respect to personality, Arroyo, Martorell, \& Tarragó (2006) argue that there is no common standard and unvarying personality for people with HA/G. Each person, in addition of having a particular and unique genetic load, lives personal experiences, and that make their personality set in a certain way. Among the personality traits of gifted children presents noting: 1) ethical and moral well-developed sense: they are concerned with the abstract concepts of good and evil, right and wrong, justice and injustice; being sensitive against social problems; 2) leadership: many of the gifted people are able to influence their peers and may become very popular and respected; 3) large perfectionism: when performing a task, especially when it is within some of their fields of interest, they usually put too lofty goals; 4) highly developed self-knowledge: they usually understand their intellectual processes and know what their main cognitive faculties are; 5) high sensitivity: they show sensitivity to the world of knowledge and are likely to experience emotions with people around them. According to the authors, other features can be also stressed, such as: perseverance, sense of feeling different, having concept of themselves added to the discontent, ingenuity and imagination.

Regarding Creativity, Arroyo, Martorell, \& Tarragó (2006) also argue that gifted axis have a high creative potential; it is an ability to generate or invent something new and original, with a spirit of invention and production of new ideas. The creative potential implies: originality (production of new ideas), fluency (the ability to generate different alternatives), flexibility (ability to generate differentiated solutions against various issues), independent thought (not being dominated by common and established), and finally, integrator (has thoughts that are able to synthesize extraordinary value).

With respect to human development as a whole, we can say that the capacities that living things have to develop occurs long before his birth, covering all stages of life; thus childhood, in a way, is an extremely important preparation for the later stages, and throughout adulthood.

The complexity of people with HA/G has not been sufficiently clear yet, because developmental biologists study the intersection between giftedness and their environmental stimuli towards a new dynamic that leads to 
higher levels of productivity and creativity.

Considering interpersonal relationships as a network in which each of us is "a point node", any action inevitably has consequences for everyone else. Humans move daily in a multitude of networks, which leads them to interact with their principles of nodes and nodes of other persons, and increasingly needs to adapt in any stage of life, especially the adulthood.

In adult life, intellectually gifted people also have skills, capabilities and resources that facilitate their adaptation to the environment. However, we must take into account the importance of the relationship with the environment, in which people develop, favoring (or not) their overall development. We would like to draw attention to the idea that there exist two types of adults with high ability/gifted, gifted adapted and non-adapted. This differentiation creates great anticipation that we need to educate these people as children, so they can have a better forward in their lives early.

Renzulli, Sytsme, \& Berman (2003) argue that the history/human culture owes much to the creative contributions made by the majority of people that we believe are gifted and talented. Also extend the idea that, to improve the educational experience of potentially gifted youngsters, it is necessary that educators have the ability to creatively direct the education of people with HA/G by encouraging leadership and creativity.

Renzulli (apud Renzulli, Sytsme, \& Berman, 2003) described the three-ring conception of giftedness, clarifying the role of personality factors and the environment, represented by a model originally described the basic fields, with six factors, the result of literature reviews and summaries of their investigations: optimism; value; passion for a subject or discipline; sensitivity to human subjects; physical or mental energy; vision and sense of destiny. These elements are extremely important for the development of the idea of a socially constructive giftedness, with potentially critical factors for the development of people with HA/. Thus, cultivating future leaders and relevant persons to progress/in a given society, focuses on improving the human condition, increase social creative potential and future success of our global society, they will be valuable leaders, with human interests that transcend those considered purely selfish and petty.

Also Sternberg (2005), in one of his last works, emphasizes that determines the "success" of a person, in terms of its human development, is in the interplay with others, especially their peers closer in their society which intelligence is united to aspects of emotions and affectivity.

McClelland (1989) addressed the creativity in studies on various facets related to personality development, as one of the most important in terms of human development.

Still we take into account that better interpersonal relations and aspects of affectivity lead to understand the complex human nature, as pointed out by Mosquera \& Stobäus (2006a, 2008) and healthy interpersonal relationships (Mosquera, \& Stobäus, 2004).

So, we want to discuss more about these perspective of the human development (lifespan approach), specially in the direction of better understand persons with high abilities who are in these personal and professional development, his/her personality development during their lives, relating to some points of their social and cultural achievements, and learning and teaching processes.

\section{Personality Characteristics of Children}

The idea of personality has often been focused as an internal entity or process that determines the behavior of human beings. But the problem with this conceptualization is that, in changing behavior, would then only need to take into account this inner need. However, it is difficult to know the internality, especially a child, to be able to act on it and educate it. It is necessary to take into account a new angle, genetic conditions that the human being and also has external variables, which establishes their behavior, carried out in any environment.

This new position, in the sense of personality, is an attempt to study more carefully, as the person withHA/Gage, enriches its manifestations and presents their behaviors. The relationship between human activity and the cultural environment also comes from an existing design from the child's activity and the influence of the community and society as a whole organized on their actions, putting social boundaries.

The leave of a historical personality that lies in the interactions that occur between society/culture and human relations, with nuances of meaning central to children's development, from acquired behaviors and the meanings data.

The development of personal conception of learning that takes place every time we perform a socialized learning that is composed of a constellation of behaviors that develop and socialize through the stimuli coming 
from the environment. Humans, although they obey the same laws, behaves differently, what defines your personality. This behavior is directly related to experiments carried out from the first moments of performance and having thus acquired a meaning and a story, expressed in their socialization.

We have, therefore, learned behaviors that are the core of the personality, the creative capacity of a person with HA/G (and vulnerability) or contradictory aspects that may exist, occurring sometimes frustrating the learning in the social interactions.

This approach to personality, with emphasis on childhood emphasizes the classical learning theory to approach called Cultural Psychology. We believe that Personality Psychology must embrace three core dimensions: the development of learning, the process of socialization and cultural influences.

There is an intimate connection between children's learning with HA/G and the development of its most intelligent behavior and the structure of his personality. This involves placing different perspectives, closely united by what we assume to be the determinative function of the actions of people in circumstances of performance and change.

The organic design, which helps us to understand the development of quality staff, has a close relationship with the ambiance and certain actions by the needs (met or not), it may ía establish a quantitative and qualitative framework for people with HA/G. This approach, which was highly emphasized by neobehaviorism authors, is now widespread among socio-historical authors, which helps us understand the possible management of environments and semiotic dimensions.

Has central meaning to try to understand the personality of the child with HA/G as a system of action, so that leads us to the basic foundations that implicates a knowledge of cultural reference in which it is inserted. Classical authors Parsons \& Shils (1968) gave meaning to the personality through knowledge, the momentum and needs, studying the behavior at certain levels, leading to their satisfaction. This satisfaction would, as a consequence, the balance between the need and the willingness to develop more precise and refined forms of behavior. For them, the personality represents a behavioral orientation that will be modified according to the new environmental and cultural possibilities that one encounters. Integrative, evaluative and attributive personal dynamism represents qualitative behaviors.

A child learning can be considered as an attempt to lay the foundation of integration and individual adjustments within a reference group, offering elements that explain more clearly and accurately the responses of people in their culture.

The system of personality in children is an organized set of needs and provisions, from a more primal aspect, become complex and generalizing, offering consistency, hierarchy and providing structure to personality. The dynamics and personality development as well as their typical (and atypical) styles, specifically depend on the genetic structure integrating individual and social cultural/dynamics that is immersed, which may result in the integration (or not) between the system of personality and the social system.

Interesting are the contributions made by Dollard \& Miller (1950), which highlighted the role of learning in the development of personality, explaining and giving coherence to it in relation to society and, ultimately, culture.

The majority of human behavior is learned; behavior characterized by giving meaning to what Vygotsky (2001) understands how mediation between culture/person. Learned fear, guilt and other social motivations, characteristics that are presented by any individual.

Knowing better how their socialization took place, we have one of the "keys" to better understand the behavior as a whole (Stobäus \& Mosquera, 2003).

There is, moreover, the HA/G an innate "internal equipment" which provides the basis for subsequent responses, possibly embedded also in its genetic conditions, and may provide (or not) of these responses by their genetic aspects, every human being.

Porting, we repeat, the genetic basis of this offered by innate factors that allow for the detection and recognition of primary impulses by the subject and internal stimuli that are of great strength and persistence, cerebral physiological processes linked to children's behavior started to know better Neurosciences. These impulses cause the person to action, but not to guide towards, therefore, fitting that quality of action in response to their learning process. Therefore, it is necessary to know the extent of integration between basic genetics and cultural dynamics. It is very interesting to understand that the qualitative study of children's responses is integrated with the space that leads to cultural dynamics and symbolic universe.

Parsons \& Shils (1968), the system depends on the personality of direct relations established by learning and 
socialization in a culture, so that learning characteristic behavioral patterns of children's culture and adult culture includes discrimination and generalization by symbols evidenced in stocks. In looks interesting also draw attention on the role of reward, emphasized by Dollard \& Miller (1950), who believed they had the same effect as that of the momentum and provocative stimuli that were operating to increase or decrease the behavior. Today, Neurosciences uncover these ideas through neuroimages, the complex (re)organization from brain mechanisms of reward/avoidance.

Another position in which the classical authors and Cultural Psychology are the intent is to analyze the influence of social context. Therefore, they say, does not possess a complete picture of the personality only through learning, but it is critical to understand the conditions of learning. Thus we have the principles of learning, to be valid, must be examined in light of a cultural reality, to establish comprehensive databases of performances and behaviors of people in a society.

These ideas have had extreme value in the thirties of the twentieth century, and today they return to Cultural Psychology named analyzed by Cole (1999), when talking about the ecological validity and its influence on human activity in its various areas.

In our view, the development of personality environmental forces play undoubtedly significant role. Therefore, one can understand that psychoanalysts claim that unconscious conflicts, acquired during childhood, serve as the basis for the emotional problems of the adult lives of these people with HA/G.

Miller \& Dollard (1941) attempted to operationalize some ideas previously developed by Freud, not to reject aspects such unconscious processes, determinants of behavior and some of the so-called defense mechanisms. For them, the most significant was to understand the proposals for Freud, translate them to language learning theory, while carried great effort to understand the role of culture/environment on human life.

The analysis of imitation also provides a sufficiently interesting approach to personality and affect in contemporary theorizing and had its appearance in 1941, with strong similarities to the socio-historical theories and modern cultural psychoanalysis. The imitative behavior, according to these authors, presents three classes or types of manifestation. The first class is the same behavior, involving the issue of same answer through the same clue. Is imitative behavior in the second class, is called the template-dependent/mentor, which requires that there be a pair or dyad; happens when a person identifies with a leading/significant person whose response causes the response of the follower, from the simplest to the most complex imitation and imitation refined. It is fascinating to analyze the behavior of children AH/SD from the dynamics of imitation and how it is carried out, the extent to develop as social beings. Currently in Neurosciences tried to understand this development from an early age through discoveries, like neuronal chains that enable these imitations, the "mirror neurons".

Kagan (1987) also highlights the development of the child as closely linked to different social and cultural contexts and many of his ideas process are integrated into neobehaviorist theories with implications for cognitive aspects and elements of possibilities for personal growth and socialization.

The third type of imitative behavior is called copy; is when someone strives to provide a response that is identical to another person. This appears especially in situations of learning skills, both personal and cultural, sports or even in artistic activities (interesting example is the cover).

The aspect of copying is extremely important in social terms, because it leads us to understand how the perception of someone's behavior can present to us a typical model, the environment caused in which we need to develop and overcome us.

From these ideas, we would like to bring some implications for a new paradigm of personality, reflected especially in childhood. Our concern is for the revaluation of neobehaviorist theory and its approach to cultural psychology, with implications for the current forms of psychology. It would be interesting at this point, draw attention to the fact that everything has worked so far, is a chance to understand people with HA/G, joined to the problems of learning theories and cultural.

We can not dismiss the great scientific contribution made by the authors cited, especially since the second decade of this century we realize that we do not know much about the human potential, the talent and the ability to express all that is internalized and expressed in ways specific act.

We would also like to dedicate some space to Robert Sears, which emphasizes the dyadic action based on the action within. Since 1943, Sears was concerned with the study of concepts of psychoanalysis and became convinced of the significant importance of parent-child relationships and their potential for fruitful learning theory. Sears (apud Sears, MacCoby, \& Lewin, 1957) organized learning theory on the basis of psychoanalytic theory and in parallel to this form; was concerned with the themes of dependency and identification during the early 
years of childhood. To quote you, we are concerned to understand the process of identification which was built by Freud, which seems to act on the beginnings of learning and at the same time, building the best and most valid high skills. Here is another realization of the importance of HA/G being identified as such.

Therefore, good development is based on the preparation of suitable conditions depend permittivity and opportunity (or harm) and the determination of suitable actions to promote limits and shapes increasingly independent control.

The child begins to behave in accordance with the guidance and control of the parents and, later, in the context of others, such as caregivers and educators. As this driving, can develop. Behavior is a product of the immediate social experience of its creation. Therefore, child development is the visible result of the creative efforts of parents (and other adults). i.e., the child's development is a result of learning (social). Therefore, the differences between human beings would be rooted in differentiated learning undertaken in their culture. Likewise, the levels of demand and pressure society places through adults near it would cause behavioral difference and diversity of personality types.

All this leads us to conclude that more rigorous study of the child's personality can be established to the extent that work with learned behaviors in real situations (different from "lab"), developing thereby a more real sense of the behavior of $\mathrm{HA} / \mathrm{G}$, avoiding exaggerated his "idealization”, trying to understand how that person develops in a particular society/culture and how their responses can cause behaviors that often not well understood.

We would close these considerations citing Kagan (1987), when he calls attention to the fascination of determinism in childhood and makes clear that the problem of development lies in the very intersection of what is known as genetic inheritance and sociocultural influence. It is not easy, according to this author, to determine how people can and should react in their cultures; have to learn about the experiences of children and the answers that are given in ambiences, because in that best known as the dynamic order of birth, identification and historical time, learn more about the quality of performance and creativity.

\section{Adulthood}

After having drawn attention on childhood development, focusing on the HA/G, we are concerned now emphasize the stage of adulthood, while remembering adolescence, because HA/G are continuous throughout life.

We are convinced that the problem of HA/G is a challenging problem for the coming ages. VandenplasHolper (2000) note that the development of human life, especially in adulthood, is a "fabric of relations" complex and intertwined. From the 70s of XX century, a network of researchers, which Paul Baltes can be considered the leader, was involved very actively in the formulation of the theoretical principles that guide the study of development throughout life, and achievement of many scientific investigations that fall within the conceptual framework thus developed. Among the researchers highlight Schaie, Willis, \& Lenner, who worked in different universities of the United States. Also stood out as very creative researcher Klaus Riegel (1925-1977), a German researcher emigrated to the United States and has left a very interesting and worthwhile work.

Baltes has, since 1980, a large team of researchers at the Max-Planck Institute in Berlin. Through their research, Baltes and his colleagues defined the Developmental Psychology Throughout Life (Lifespan Approach) and formulated a body of propositions that constitute the guiding principles that guide empirical work. We can say, as he lay Baltes (apud Baltes, Staudinger, \& Lindenberger, 1999), the Developmental Psychology throughout his life interested in the description and explanation of ontogenetic changes from conception to death. As a consequence, the development will have a fundamental sense without a single explanatory status of psychological truly only based on chronological age party; this is just a "gross" variable whose psychological meaning has to be specified by reference to the psychological processes underlying the development and the conditions that the model, the social context in which people live and. Baltes define, even more explicitly in Developmental Psychology throughout life, as a study of constancy and change are manifested in human behavior throughout ontogeny, from conception until death occurs.

These basic ideas were extremely interesting to delineate the meaning of adulthood and its development in rapidly changing cultures. Clearly, adults living today, higher life expectancy and better opportunities for the future, as advances in medical and pharmaceutical field, the technology, improving the quality of life and the reconceptualization of the vital sense cause they have better conditions in their existence and more possibilities for cognitive development through their own life experiences. All that was exposed so far can be included within 
the call normative influences connected to the ontogenetic age, which consist of biological and environmental factors strongly linked to biological age. It should be clarified that the biological determinants refer to the maturation of the organism (or decline) in certain areas that characterize from a certain age. Already the environmental determinants refer to expectations that society members in their causes, and are also linked to the motivational and cognitive levels.

In the 60s of last century, the sociologist Neugarten (apud Mosquera, 1987), the University of Chicago, surveyed the expectations of adult women in relation to their vital performance, creating the idea of "social clock", which would determine the possibilities that adults have in their own existence in a social world; while Levinson (cited by Mosquera, 1987) studied men, reaching similar conclusions.

Another important aspect is normative influences, linked to the story. Consist of biological and environmental determinants associated with the historical context in which they evolve different groups of adults. Therefore, given generation is important in order to understand the level of thought and the level of motivation that appears in a given historical moment.

Another very important aspect is the significant life events, the non-normative nature, which may appear as cracks or cuts at some point in life in which each person reacts in a unique way, in a unique way.

It is evident that the frame of reference for the development throughout the life outlined by Baltes is a paradigm in size and not a theory. Thus, we are still different theoretical and methodological aspects of special relevance, taking into account the achievements made by polls, which allow views of development from perspectives such as cognitive, emphasizing its structure and its decline. Before entering this subject, it is interesting to present some characteristics undergone by the human being.

We can state, according to Schaie \& Willis (2003), the transition to adulthood is marked by a series of events, the most common being the end of schooling, work and be economically independent, to live outside the family, have a marriage and practice the paternity/maternity.

These events may occur simultaneously or sequentially and in fact, the timing and pattern may vary depending on individuals and their generation. As ever, we pointed out earlier, social expectations and historical scenarios determine these events.

We must remember that Erikson, according to explain Schaie \& Willis (2003) introduced the concept of identity crisis to describe the period in adolescence that often takes place, in which the developing person must integrate new skills, feelings, roles and a new physical appearance. Cognitive development is extremely important to be able to detect the possibility of HA/G at the same time sharpens the reasons that lead humans to draw his own life.

Mosquera (1987) has highlighted that, in young adulthood, following the thought of Erikson, gives the state of intimacy $x$ isolating, marking the transition to adulthood. At this stage, the primary task is to establish intimate relationships without losing the identity and independence, and isolation occurs when a person's defenses are too strong to permit him to union with another.

It would be interesting to talk now about the problems of love, which Mosquera (2004) has been working since 1979. We could say that the emotional development occurs immediately after birth and goes a long way through the steps determined by age and culture that characterize the evolution human. If the first relevant experiences are of great importance, as well as subsequent experiments, all shape the dynamics of life in its vital structure. Love is a unique, multi-faceted but sentiment, expressing the need to live and stay in other people. The freedom of love is unique for its permanence and quality, which is the spontaneity of the donation and the desire to transcend to others, without the need to manipulate them or make them our cravings continuity condition. Remember the importance of (self) motivation for the development and learning (Mosquera \& Stobäus, 2006b; Mosquera, Stobäus, \& Freitas, 2013; Mosquera, Stobäus, \& Freitas, 2014; Stobäus \& Freitas, 2012), alsomentioning the ideas of Maslow (1954).

The young adult with HA/G also faced with the task of determining their relationship with the community. It may be that the religious identity and political commitment are important for him to feel involved in the community. Another key aspect is the attempts to develop a life plan, philosophical and epistemological, which do penetrate more appropriately called the period of middle adulthood.

Controversy exists as to which ages are critical periods of life (Stobäus \& Mosquera (2004, 2013). Thus, young adulthood would be approximately 18 - 20 and 35 years, while the middle adulthood, according to several criteria, can get between 35 and 40 years and finish between 65 and 70 years. We must remember that according to the ideas expressed above, age is a variable "gross", so we can say that, according to several authors point out, 
is a term that implies the generativists and productivity at home and at work.

Moreover, at various times of the average adult life people find themselves involved in caring for their young children and teenagers, and consequently of their aged parents, and have to take care of themselves. These three generations are often in close contact, in our society; so taking care of elderly parents has become a normative part of middle adulthood.

We often worked with average adults who tell us a chance to understand the tragedies and the changes that occur during this stage of life. Can be a time of great growth and opportunity for self-actualization and at the same time, a period of crises and depressions. Either way, terms like "menopause" and "andropause" reveal physiological and psychological changes that people experience alongside some conflicts that are closely linked to satisfaction/dissatisfaction and crises faced in this step to.

In middle adulthood is extremely important to the creative power and the ability to develop more productive and ingenious ideas; so it is very important to stimulate and develop the best conditions and skills of imagination, fantasy and creativity.

The third stage of adulthood, termed by authors of late adulthood and aging, according to Schaie \& Willis (2003), can be divided into three sub-stages: the vigorous young elders, slower elders and the elders too. According to these authors, the three groups differ significantly.

The young elders remain active and behave in many ways like in middle adulthood. This proves, in a way, we can extend our ability to remain young and active for much longer.

Slower elders also show a higher incidence of physical injuries, but many are able to live a full life, using aids. The very elderly, characterized today as over 90 years of chronological age, are often physically and mentally disabled, and need a system of intensive help, sometimes in institutions and are therefore more dependent.

In general terms, the concern is trying to stay upright and not "fall into despair", and also have emotional and economic security. This is desirable in order to achieve greater creative, scientific and artistic production.

Aging can be a time of great personal achievement; it can provide the opportunity to be involved in the exploration of options that were not possible before because of family or work issues. The Healthier aging is a process of selective optimization and compensation. Moreover, this process is to maximize the interpersonal and environmental support; so most seniors who have aged better have spare capacity that leads them to be wiser.

Vandenplas-Holper (2000) states that investigations Riegel concerned the development of cognitive skills during the period of adult life, which took place between the 50 years until his death. Riegel proposed different explanations for the fact that, throughout adult life, there were larger or smaller declines in cognitive ability and, therefore, came to the conclusion that it may be admitted that some people would have higher cognitive abilities and superior longevity. This would be associated with biological factors as well as psychological factors. This possibility would be intrinsically linked to dialectical terms and, therefore, we come to the conclusion that the body is not a "passive receiver" of environmental stimuli. Instead, print your brand on the environment, modifying it and being changed by it. Still referring Riegel, affirm that organism/medium influence is reciprocal and dialectical.

In conclusion of this session, we call attention that there is increasing refinement in research and theories, as very possible to understand that cognitive-existential dimension is of fundamental importance in order to understand the evolution of human potential, not only in childhood and adolescence but especially on the road to adulthood to death.

\section{Conclusion}

Our work started from the psycho-social approach to positive psychology background; we consider the enormous importance and scope. Besides reviewing some aspects the development of human life from a holistic perspective, we present child development and adult by great features, like an approach in two stages of life, from childhood to adulthood, their challenges, their strengths and potential crises.

We believe we can find people with High Ability/Gifted motivated for their achievement and cognitive, affective and social development. We also believe that an education is necessary for the future that will bring us greater opportunities to stimulate talent, reaching viable solutions to make a better world, and we have more positive elements into consideration to accept, understand, live and help those people in their development with High Abilities/Gifted persons; they deserve living together well and healthily developing their skills and abilities. 


\section{References}

Arroyo, S., Martorell, M., \& Tarragó, S. (2006). La realidad de una diferencia: Los superdotados_Diagnóstico, asesoramiento, atención escolar, integración social. Barcelona: Terapias Verdes.

Baltes, P., Staudinger, U., \& Lindenberger, U. (1999). Lifespan Psychology: Theory and Application to Intellectual Functioning. Annual Reviews Psychology, 50, 471-507. http://dx.doi.org/10.1146/annurev.psych.50.1.471

Cole, M. (1999). Psicología Cultural. Madrid: Morata. [Original (1996). Cultural Psychology: A Once and Future Discipline. Cambridge, MA: First Harvard University Press].

Dollard, J., \& Miller, N. E. (1950). Personality and Psychoterapy. New York: McGraw-Hill.

Kagan, J. (1987). El niño hoy. Madrid: Espasa-Calpe. [Original (1984). The Nature of the Child. New York: Basic Books].

Maslow, A. H. (1954). Motivation and Personality. New York: Harper and Row.

McClelland, D. C. (1989). Estudio de la motivaciónhumana. Madrid: Narcea. [Original (1987). Human Motivation. Cambridge: Cambridge University Press].

Miller, N. E., \& Dollard, J. (1941). Social Learning and Imitation. New Haven: Yale U. Press.

Mosquera, J. J. M. (1987). Vida adulta. 3. ed. Porto Alegre: Sulina.

Mosquera, J. J. M., \& Stobäus, C. D. (2006a). Afetividade: A manifestação de sentimentos na educação. Educação-PUCRS, Ano XXIX, 1, 123-133.

Mosquera, J. J. M., \& Stobäus, C. D. (2006b). Vida Adulta: Superdotação e Motivação. Revista Educação Especial, 28, 233-246.

Mosquera, J. J. M., \& Stobäus, C. D. (2008). O professor, personalidade saudável e relações interpessoais: Por uma educação da afetividade. In D. Enricone (Org.), Ser professor (6th ed., pp. 73-90). Porto Alegre: EdiPUCRS.

Mosquera, J. J. M., Stobäus, C. D., \& Freitas, S. N. (2013). Altas Habilidades/Superdotação: Abordagem ao longo da vida. Revista Educação Especial, 26, 401-420.

http://cascavel.ufsm.br/revistas/ojs-2.2.2/index.php/educacaoespecial/article/view/5371

Mosquera, J. J. M., Stobäus, C. D., \& Freitas, S. N. (2014). Altas Habilidades/Superdotação no Transcurso da Vida: Da Infância à Adultez. In A. M. R. Virgulim, \& E. C. Konkkiewski (Org.), Altas Habilidades/Superdotação, Inteligência e Criatividade (pp. 283-308). Campinas-SP: Papirus Editora.

Papalia, D. E., Olds, S. W., \& Feldman, R. D. (2010). Desenvolvimento Humano (10th ed.). São Paulo: McGraw Hill. [Original (2008). Human Development (9th ed.). New York: McGraw Hill]

Parsons, T., \& Shils, E. A. (1968). Hacia una teoría general de la acción. Buenos Aires: Kapelusz. [Original Parsons, T., \& Shils, E. A. (1951). Toward a General Theory of Action. New York, Harper \& Row]

Renzulli, J. S., Systme, R. E., \& Berman, C. (2003). Ampliando el concepto de superdotación en cara a educar líderes para una comunidad global. In J. A. Alonso, J. S. Renzulli, \& Y. Benito (Eds.), Manual Internacional de Superdotados (pp. 71-87). Madrid: Artedis.

Schaie, K. W., \& Willis, S. (2003). Psicología de la Edad Adulta y la Vejez. Madrid: Pearson Educación. [Original (2002). Adult Development and Aging. Upper Saddle River, NJ: Prentice Hall].

Sears, R. R., MacCoby, E. E., \& Lewin, H. (1957). Patterns of Child Rearing. New York: Harper.

Sternberg, R. (2005). Inteligência de Sucesso-Como a inteligência prática e a criativa são determinantes para uma vida de sucesso. Lisboa: Ésquilo. [Original (1997). Successful Intelligence: How Practical and Creative Intelligence Determine Success in Life. New York: First Plume Printing]

Stobäus, C. D., \& Freitas, S. N. (2012). Olhando as Altas habilidades/Superdotaçãocom as lentes dos estudos curriculares. In C. D. Stobäus, \& J. J. M. Mosquera (Eds.), Educação Especial: Em direção à Educação Inclusiva (4th ed., pp. 31-47). Porto Alegre: EdiPUCRS.

Stobäus, C. D., \& Mosquera, J. J. M. (2003). A criança com necessidades educativas especiais: uma visão ampla e aportes educacionais. In R. Krebs, F. Copetti, T. Beltrame, \& R. Pinto (Eds.), Os processos desenvolvimentais na infância (pp. 13-28). Belém-PA: GTR Gráfica e Editora.

Stobäus, C. D., \& Mosquera, J. M. M. (2004). Educação Especial: Em direção à Educação Inclusiva (2nd ed.). Porto Alegre: EdiPUCRS. http://www.pucrs.br/edipucrs/digitalizacao/diversos/85-7430-354-2.pdf

Stobäus, C. D., \& Mosquera, J. J. M. (2013). Educação e inclusão. Perspectivas desafiadoras. Porto Alegre: EdiPUCRS.

Vandenplas-Holper, C. (2000). Desenvolvimento psicológico na Idade Adulta e durante a velhice (maturidade e sabedoria). Lisboa: ASA. [Original (2003). Developpement Psychologique a L'ageadulte et pendant la vieillesse (2nd ed.). Paris: PUF]

Vygotsky, L. S. (2001). A construção do pensamento e da linguagem. São Paulo: Martins Fontes. [Original (1987). Thinking and Speech. New York: Plenum Press] 